\title{
Talking the wrong talk?
}

If a serious commitment were made to produce a quality Fijian daily, I don't doubt that it would soon outsell all the English ones. Next time anyone in the Fiji media suggests that a major problem today is that the Fijian people are so ill-informed, maybe they should question the Fiji media.

\section{BY PAUL GERAGHTY}

WITH three daily newspapers, numerous periodicals, two television stations, and a host of radio stations, you'd be tempted to call Fiji's media healthy, even vibrant. But there's just one little problem. Consider, for example, a nation such as Belgium. Approximately 39 percent of the population speak French, 60 percent speak Dutch, and maybe 1 percent speak German. Accordingly and unsurprisingly, the language of the vast majority of media output is French and Dutch. But if German was the language of all the daily newspapers in Belgium and most of the other media, would we consider that to be a healthy situation? I think not - we would say that the media are not serving the people. We would say that the French and Dutch speakers, who constitute the bulk of the population, are being deprived of their right to information and all the other benefits of the media, and that the media are giving an unfair advantage to the German-speaking minority.

So why are we so willing to accept a similar situation in Fiji? Something like 50 percent of the population have Fijian as their first language, and maybe 45 percent speak Fiji Hindi. There are in fact far more speakers of Rotuman in Fiji than there are first-language speakers of English. So with all three daily newspapers and all periodicals in English only, as is the case also with most of the broadcasting time - is this not a very blatant case of tyranny by the minority?

Let me put it another way. After the Belgian football team has performed 164 PACIFIC JOURNALISM REVIEW 7:1 2001 
FIJIAN-LANGUAGE PRESS

and the nation has watched on TV (usually, it has to be said, not very impressed with their performance), some of the players will be interviewed in French and some in Dutch, and some who are bilingual will be interviewed in both Dutch and French, and the public will hear and understand their responses. Some will no doubt be translated simultaneously, or later dubbed or translated with subtitles. In the end, everyone knows what excuses the players have come up with for the latest national embarrassment. Switch now to the National Stadium at Muanivatu (if it were actually situated in Laucala it would sink into the mangrove swamp, but that's just by the way). Our boys have just earned a win and the nation is agog to hear the words of wisdom of the players. The TV interviewer is a native speaker of Fijian, as are all the players interviewed, as are indeed most of the people watching. Yet the whole process is done in a language that is foreign to them all. Isn't this whole charade a bit silly?

In my opinion it is - but there are of course what might be called mitigating circumstances that make the situation in Fiji rather different from that in Belgium. That doesn't mean however that we should accept the situation and not attempt to change it.

Before I proceed I should explain that my remarks will be directed primarily at the Fijian language. The situation with regard to Hindi is to some extent comparable, and much of what I have to say will also apply to Hindi; but at the same time there are some important differences, notably that the standard Hindi language is very different from that spoken in Fiji, and uses an alphabet that many local Hindi-speakers are not very familiar with. We should bear in mind also that the Fijian language is not spoken only by Fijian people. It is also the first language of practically all the Melanesian community, and of a considerable number of part-Europeans, Rotumans, Chinese, and various Pacific Islanders, as well as being a major language of inter-communal communication.

The main reason for our media being so skewed in favour of English is simply historical: Fiji was a British colony for nigh on a hundred years, and it has been argued that it is still in a sense a colony of the largely English-speaking nations of the nearby antipodes. For the same reason most media in French Polynesia still favour French, though Tahitian is the everyday language of conversation.

Still, this is not the whole story. After all, Indonesia, Malaysia, the Philippines and even India all have long histories of colonisation, but the local language media in these countries are very strong. One consideration of course is the economy of size - these countries have populations in the tens or even 
hundreds of millions. Another factor is that Fiji has a rather different history from these other colonies. Literacy is relatively new, and very imperfectly developed. For the first 90 years or so of literacy in Fijian, education in Fiji was largely in the hands of the missions, and Fijian was used as the main language of instruction. In the 1920s there were Fijian language text-books for all the subjects that were then being taught - arithmetic, history, geography, health science, Fijian, English and even Latin. But since the entrusting of education to New Zealand authorities around 1930, Fijian (like Maori was then in New Zealand) has been practically banned from Fiji's schools. There are still, incredibly, many schools where students are punished for speaking their native language. The end result is that many Fijian-speakers are only minimally literate, that is, they can read and write in Fijian, but actually use that literacy very little, if at all.

Then there is the "bridge" myth, a hoary old excuse that still gets the occasional airing even today. As part of their rationalisation for ignoring Fijian (and Hindi), colonial educational authorities put forward the theory that English is essential as a bridge between the two major communities. This is of course patently absurd; it would be equally ridiculous to claim that in order for all French-speaking and Dutch-speaking citizens of Belgium to get along, they must all learn German. The obvious way for people of different cultures to get along is to learn about and respect each others' language and culture, not to attempt to communicate through a language which is foreign to both communities. There is also a more sinister reason for the persistence in the media and elsewhere of a language very few people speak - the existence of a postcolonial elite who believe it to be to their advantage to be more colonial than the actual colonists ever were. Many Fijian-speakers in positions of power do not want to see access to information or to government services made easier to ordinary Fijians through the use of their language, for the simple reason that the elite derive much of their own power from their knowledge of English, and expanded use of Fijian would make them redundant. So, even though the 1997 constitution stipulated that all Fijian and Hindi speakers are entitled to government services in their own language, no steps were ever taken to implement this ideal, and speakers of languages other than English continued to be treated as second-class citizens. There was maybe an excuse in the colonial era for the neglect of local languages, because many of those in positions of power simply couldn't speak them. Now that they have been replaced by people who are themselves speakers of local languages, that excuse is no longer valid.

166 PACIFIC JOURNALISM REVIEW 7:1 2001 
Maybe, you may say, English is still the most effective means of communication, because it's taught in schools and most Fijians can read it well enough. Maybe you're right (though I doubt it). The thing is, we simply don't know anything about the effectiveness of different languages in the media in Fiji. It sounds to me like a question either the Fiji government or an institution like the University of the South Pacific should have tackled eons ago, but to my knowledge the only nod in that direction ever made was a very small-scale study by USP's Makareta Waqavonovono published about 20 years ago in Pacific Perspective. Millions of dollars are spent locally every year on publicity campaigns of all sorts, from driving to alcohol abuse to health and nutrition, and in most cases they are all in English, and simply mindless repetitions of what is done overseas - and nobody has a clue as to whether they make the slightest difference to public awareness or not.

You may argue then that English newspapers sell far more than Fijian newspapers, which proves that they are more effective media. That more copies are sold is undoubtedly true, even though there hasn't been an independent survey recently to determine exactly what the figures are.

What I would argue is that sales figures can be misleading, because the average readership of one Fijian newspaper is considerably greater than that of an English-language newspaper - perhaps a ratio of something like five to one would not be an exaggeration. More importantly, if even a tenth of the funding and resources and general commitment that go into the production of Englishlanguage newspapers was diverted to Fijian-language newspapers, then we might see a dramatic rise in readership. Many Fijian-speakers are not interested in Fijian-language newspapers simply because they are, on the whole, of such poor quality. If a serious commitment were made to produce a quality Fijian daily, I don't doubt that it would soon outsell all the English ones. Just because we can understand the reasons for the status quo, it doesn't mean that we should meekly continue with it. That is surely to deny the main reason for the existence of media. So next time anyone in the Fiji media suggests that a major problem today is that the Fijian people are so ill-informed, maybe they should wonder whether the Fiji media themselves are not part of the source of that problem.

Dr Paul Geraghty is senior lecturer in linguistics at the University of the South Pacific. This article originally appeared in a shorter form in Wansolwara, September 2001, as "Are Fiji's news media talking the wrong talk?" geraghty_p@usp.ac.fj 